\title{
ANTI HYPERGLYCEMIC EVALUATION OF TERMINALIA CHEBULA LEAVES
}

\author{
JAYASHREE DUTTA*, MOHAN CHANDRA KALITA \\ Department of Biotechnology, Gauhati University 781014 \\ Email: jshrdtt@gmail.com
}

Received: 27 Jul 2018 Revised and Accepted: 26 Sep 2018

\begin{abstract}
Objective: The antihyperglycaemic potentiality of Terminalia chebula leaves has not yet been investigated thoroughly compared to its fruit counterpart. Therefore, the purpose of this study was to assess the hypoglycaemic potentiality of Terminalia chebula Retz leaves both in vitro and in vivo.

Methods: Fresh leaves of T. chebula were collected, authenticated and grounded to a fine powder. The powdered material was extracted in methanol. The hypoglycaemic potentiality of the extract was accessed in vitro using enzyme alpha-amylase and alpha-glucosidase. The antihyperglycaemic activity of the methanol extract active fraction was accessed in vitro and in vivo. The active fraction thus obtained was partially characterized using Fourier transform infrared spectroscopy (FTIR) and High-performance liquid chromatography (HPLC) analysis.

Results: The crude leave methanol extract of Terminalia chebula demonstrated $100 \% \alpha$ glucosidase inhibition with IC50-0.956 \pm 0.342 mg/ml compared to standard drug acarbose. Oral administration of the active fraction to diabetic rats loaded with maltose significantly (P<0.05) retarded the postprandial spike of blood glucose level compared to standard drug acarbose. Partial characterization of the fraction reveals the presence of
\end{abstract} hydrosoluble tannin gallic acid.

Conclusion: The study provides an in vitro and in vivo rationale evidence of Terminalia chebula leaves to retard postprandial hyperglycemia.

Keywords: Terminalia chebula, Postprandial hyperglycemia (PPHG), $\alpha$ amylase, $\alpha$ glucosidase, Active fraction (f5)

(C) 2018 The Authors. Published by Innovare Academic Sciences Pvt Ltd. This is an open-access article under the CC BY license (http://creativecommons.org/licenses/by/4.0/) DOI: http://dx.doi.org/10.22159/ijpps.2018v10i11.28167

\section{INTRODUCTION}

Diabetes mellitus is a metabolic disorder characterized by high blood glucose level. Diabetes mellitus is caused due to relative or absolute deficiency of insulin or resistance to the action of insulin at the cellular level [1]. The abnormalities in metabolism of carbohydrate protein and fat are due to a deficient action of insulin on target tissues resulting from insensitivity or lack of insulin [2]. In developing countries, diabetes mellitus type 2 represents near about $90 \%$ of total people with diabetes. The percentage is much higher in developing countries [3]. One of the prominent and early symptoms of diabetes mellitus type 2 is postprandial hyperglycemia (PPHG). Postprandial hyperglycemia has been identified as an independent risk factor for developing cardiovascular disease in patients with or without diagnosed diabetes. Studies have shown that PPHG, instead of Fasting glucose, is a significant predictor of subsequent myocardial infarction and death in patients with newly diagnosed diabetes mellitus type 2 [4]. Drug with mild $\alpha$ amylase inhibition is considered as preferable for treatment of postprandial hyperglycaemia since the side effects related to very high inhibition of pancreatic $\alpha$-amylase such as flatulence, abdominal distension, and diarrhoea etc caused by intake of drug acarbose, results in abnormal fermentation of undigested carbohydrate by of colon bacteria mark limitation in its use [5]. Therefore, $\alpha$-glucosidase inhibitors are considered as better therapeutic to control the PPHG spike in diabetes mellitus type 2. Terminalia is a genus of large trees of the flowering plant, family Combretaceae, comprising around 100 species distributed in tropical regions of the world. Being a native plant of South East Asia, the dried ripe fruit of Terminalia chebula has traditionally been used to treat various aliments including diabetes [6-9]. Though several studies were conducted earlier upon the fruit part of T. chebula, the literature survey reveals that there is no previous report on the hypoglycaemic evaluation of the leaf part of the plant T. chebula, both in vitro and in vivo. Hence, in the current study, the leave methanol extract of the plant was used to access its hypoglycaemic potentiality in vitro and in vivo.

\section{MATERIALS AND METHODS}

\section{Chemicals and reagents}

Alpha-glucosidase (EC 3.2.1.20) porcine pancreatic alpha-amylase enzyme (3.2.1.1) and alloxan monohydrate were procured from Sigma Co. USA. Standard drug acarbose was purchased from a nearby pharmaceutical shop of Guwahati. For estimating the blood glucose level, Glucometer Select One-touch was used. All solvent used in this study were of analytical grade.

\section{Collection of plant material}

Fresh leaves of Terminalia chebula Retz were collected from nearby areas of Gauhati University. The plant material collected was authenticated in the Department of Botany, Gauhati University, Guwahati with reference No. Herb/Bot/GU/2015/123 Terminalia chebula Retz family-Combretaceae (Acc. No.18084). Voucher specimens of the collected plant were deposited at Department of Botany, Gauhati University.

\section{Preparation of plant extract}

Collected leaves were shade dried, grounded to the fine powder and extracted subsequently in methanol, using a Soxhlet apparatus. The crude extract was concentrated using a rotary evaporator (BUCHI R II). The semisolid extract obtained was then stored at $4{ }^{\circ} \mathrm{C}$ until the assay.

\section{In vitro Alpha amylase inhibition assay of $T$. chebula extract}

$\alpha$-amylase inhibition was determined using the modified version of the method according to Bernfield [10]. Briefly, $100 \mu \mathrm{l}$ of test extract was allowed to react with $200 \mu \mathrm{l}$ of the porcine pancreatic alphaamylase enzyme (Sigma Aldrich-3176) of $0.5 \mathrm{unit} / \mathrm{ml}$ and $100 \mu \mathrm{l}$ of 2 mmol of sodium phosphate buffer (pH 6.9). After 20 min of incubation at $37{ }^{\circ} \mathrm{C}, 100 \mu \mathrm{l}$ of $1 \%$ potato starch solution was then added. The same was performed for the blank, where $200 \mu \mathrm{l}$ of an enzyme was replaced by the buffer. After incubation for $15 \mathrm{~min}, 500$ $\mu \mathrm{l}$ of 3, 5 Dintro salicylic acid reagents were added to both control and test. They were kept in a boiling water bath for $10 \mathrm{~min}$. The absorbance was recorded at $540 \mathrm{~nm}$ using a UV-VIS spectrophotometer and the percentage of inhibition of alphaamylase enzyme was calculated using the formula.

$$
\text { Inhibition }(\%)=\frac{\Delta \text { Acontrol }-\Delta \text { Asample }}{\Delta \text { Acontrol }} \times 100
$$


Where $\Delta \mathrm{A}$ is the absorbance of the control reaction, $\Delta \mathrm{A}$ sample is absorbance of the test sample reaction.

$\Delta \mathrm{A}$ control $=$ Absorbance Test-Absorbance Blank $\Delta \mathrm{A}$ sample

\section{Absorbance Test-Absorbance Blank}

Positive controls and suitable reagent blank were simultaneously carried out and subtracted. The Inhibition percentage (\%) was plotted against sample concentration $(2,4,6,8,10 \mathrm{mg} / \mathrm{ml})$ and a logarithmic regression curve was obtained to calculate the $\mathrm{IC}_{50}$.

\section{In vitro Alpha-glucosidase inhibition assay of $T$. chebula extract}

$\alpha$-glucosidase inhibitory activities of all collected plant extract were conducted according to standard protocol [11]. $100 \mu \mathrm{l}$ of plant extract was allowed to react with $100 \mu \mathrm{l}$ of $20 \mathrm{mmol}$ pNPG ( $p$ Nitrophenyl $\alpha$-D glucopyranoside, Himedia RM 10294). To that mixture, $2.2 \mathrm{ml}$ of $100 \mathrm{mmol}$ phosphate buffer at $\mathrm{pH} 7.0$ was added and then incubated for $10 \mathrm{~min}$ at $37^{\circ} \mathrm{C}$. The reaction was initiated by addition of $100 \mu \mathrm{l}$ of alpha-glucosidase from Saccharomyces cerevisiae (Sigma, G5003) solution ( $1 \mathrm{mg} / 0.1 \mathrm{ml})$. It was followed by 15 min incubation at $37^{\circ} \mathrm{C} .2 .5 \mathrm{ml}$ of $200 \mathrm{mmol} \mathrm{Na} 2 \mathrm{CO} 3$ was added later, to stop the reaction. The absorbance of $p$ Nitrophenol released from PNPG was measured in Spectrophotometer at $400 \mathrm{~nm}$. The inhibition percentage of $\alpha$-glucosidase activity was calculated by the following equation:

$$
\text { Inhibition }(\%)=\frac{\Delta \text { Acontrol }-\Delta \text { Asample }}{\Delta \text { Acontrol }} \times 100
$$

Where, $\Delta \mathrm{A}$ is the absorbance of the control reaction, $\Delta \mathrm{A}$ sample is absorbance of the test sample reaction.

$\Delta \mathrm{A}$ control $=$ Absorbance Test - Absorbance Blank $\Delta \mathrm{A}$ sample $=$

Absorbance Test-Absorbance Blank

A dose-dependent alpha-amylase and alpha-glucosidase inhibitory activities were measured using an increasing concentration of plant sample $(2,4,6,8,10 \mathrm{mg} / \mathrm{ml})$ and the IC $_{50}$ was calculated, IC $_{50}$ denotes that concentration of plant extract that is required to inhibit $50 \%$ of enzyme activity.

\section{Induction of diabetes to experimental animal model}

Wistar rats (150-220 g) of either sex were used in this study. The rats were purchased from Assam veterinary college, Guwahati and Department of Zoology, Gauhati University. The animals were maintained under standard laboratory conditions at $25 \pm 2{ }^{\circ} \mathrm{C}$ and a normal photoperiod of $12 \mathrm{~h}$ light and $12 \mathrm{~h}$ dark cycle. The animals were made free access to water and standard diet. The experimental protocol was approved by Institutional ethical committee (NumberIACE/PER/2015/01) of Gauhati University. Rats overnight fasted were given a single intraperitoneal injection of $155 \mathrm{mg} / \mathrm{kg}$ body wt. alloxan monohydrate (Sigma, USA) dissolved in freshly prepared normal saline $(0.9 \%)$. Animals with fasting blood glucose over 200 $\mathrm{mg} / \mathrm{dl}$, five days after alloxan administration were considered diabetic and were further taken for experimental studies.

\section{Oral carbohydrate tolerance test of $\mathrm{MeOH}$ extract of $T$. chebula} leaves

\section{Oral glucose tolerance test}

For oral glucose tolerance test experimental animals were divided into two groups, normal and diabetic comprising of three subgroups consisting of six rats $(n=6)$ in each group; In the Normal experimental group, three subgroups were there. Group I, Normal control rats received normal saline ( $5 \mathrm{ml}$ vehicle); Group II, Normal rats treated with Plant extract in normal saline $(300 \mathrm{mg} / \mathrm{kg}$ body weight); Group III, Normal rat treated with acarbose in normal saline $(10 \mathrm{mg} / \mathrm{kg}$ body weight). Diabetic experimental groups: three subgroups were there. Group I, Diabetic control rats receiving normal saline (vehicle); Group II, Diabetic rat treated with plant extract in normal saline (300 mg/kg body weight). Group III, Diabetic rat, treated with acarbose in normal saline $(10 \mathrm{mg} / \mathrm{kg}$ body weight). Thirty min after administration of vehicle (Normal saline), plant extract and acarbose respectively, all rats were given orally, glucose ( $2 \mathrm{~g} / \mathrm{kg}$ body weight). The Postprandial blood glucose levels were measured before $(0 \mathrm{~min})$ and at 30,60 and $120 \mathrm{~min}$ using a glucometer. Postprandial blood glucose curves of experimental rats were plotted and compared with those of control rats.

\section{Oral maltose tolerance test}

Six days after performing the glucose tolerance test, maltose tolerance test was performed in the same group of rats. The procedure for performing the maltose tolerance test was similar with glucose tolerance except that instead of glucose, maltose (3g/kg body weight) was orally administrated to all groups of rats, 30 min after administration of the plant extract.

\section{Oral starch tolerance test}

Six days after performing the maltose tolerance test, starch tolerance test was performed in the same group of rats. Starch ( $3 \mathrm{~g} / \mathrm{kg}$ body weight) was orally administrated to all groups of rats, 30 min after administration of the plant extract.

\section{Bioassay-guided fractionation and partial characterization of} crude methanol extract of $T$. chebula leave

The crude methanol extract of T. chebula leaves was subjected to column chromatography using silica gel 60-120 mesh for the isolation of bioactive antidiabetic principles. The column (300 x 18 $\mathrm{mm}$ diameter) was packed with slurry of silica and petroleum ether and kept for overnight. Next morning plant sample (crude methanol extract of $T$. chebula leaves in powder form) was loaded over the packed column with the help of a spatula. The column was eluted with a solvent of increasing polarity. All fractions were analyzed in Merck TLC plates $(20 \mathrm{~cm} \times 20 \mathrm{~cm})$ using a different proportion of hexane and ethyl acetate as mobile phase. Obtained fractions were tested for their in vitro hypoglycemic property using alpha-amylase and alpha-glucosidase enzymes using the same protocol mentioned earlier. The fraction showing highest in vitro hypoglycemic activity was finally accessed for its maltose tolerance in vivo in an alloxaninduced diabetic rat model using the pre mention protocol. The isolated active fractions or band was further characterized using FTIR analysis for the identification of the active principle group involved in retarding the postprandial hyperglycemia.

\section{Statistical analysis}

The results obtained were expressed in mean \pm SEM. The studied groups were compared using ANOVA test and Post Hoc Turkey HSD analysis was done to compare the mean. Values were considered to be significant when the p-value was less than 0.05 .

\section{RESULTS AND DISCUSSION}

When accessed for $\alpha$-amylase inhibitory activity at the concentration of $10 \mathrm{mg} / \mathrm{ml}$, a mild inhibition of $70.46 \%$ was demonstrated by the extract compared to standard drug acarbose $80.21 \%$. Whereas in case of enzyme alpha-glucosidase the same leave extract demonstrated a remarkable $100 \%$ inhibition compared to standard drug acarbose with $85.34 \%$ with a very minimum IC50 value of $0.956 \pm 0.342 \mathrm{mg} / \mathrm{ml}$ (table 1$)$.

Table 1: Alpha amylase and alpha glucosidase inhibitions-IC50 value calculation of Terminalia chebula leaves and standard drug acarbose, values are expressed as mean $\pm \operatorname{SEM}(n=3)$

\begin{tabular}{llll}
\hline $\begin{array}{l}\text { Studied } \\
\text { plant }\end{array}$ & $\begin{array}{l}\text { Alpha amylase IC50 } \\
\text { Value }(\mathbf{m g} / \mathbf{m l})\end{array}$ & Acarbose $\mathbf{( m g} / \mathbf{m l})$ & $\begin{array}{l}\text { Alpha glucosidase } \\
\text { IC50 value (mg/ml) }\end{array}$ \\
\hline $\begin{array}{l}\text { Terminalia } \\
\text { chebula } \\
\text { leaves }\end{array}$ & $06.09 \pm 0.342$ & $05.09 \pm 0.028$ & $0.956 \pm 0.342$ \\
\hline
\end{tabular}




\section{Oral carbohydrate tolerance test}

The effect of the crude extract of $T$. chebula leaves, and acarbose on oral carbohydrate tolerance test was performed in both normal and alloxan-induced diabetic rats using monosaccharide (glucose), disaccharide (maltose) and polysaccharide (starch).

\section{Oral glucose tolerance test}

A total of 36 rats were used for the carbohydrate tolerance test. The postprandial glucose variation was measured by loading both the experimental groups with glucose $(2 \mathrm{gm} / \mathrm{kg}$ body weight). In glucose tolerance test, we found that the oral administration of acarbose ( $10 \mathrm{mg} /$ body weight $), 30 \mathrm{~min}$ before oral administration of glucose to $16 \mathrm{~h}$ fasted normal and diabetic rats were capable of suppressing the postprandial blood glucose level at 60 and 120 min compared to methanol extract of $T$. chebula leaves (fig. 1 and 2).

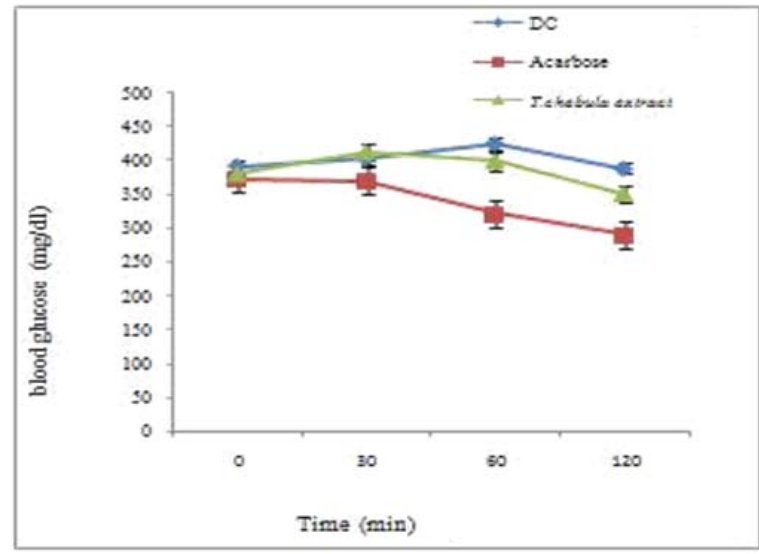

Fig. 1: Oral glucose tolerance test in diabetic control (DC), values expressed as the mean $\pm \operatorname{SEM}(n=6)$

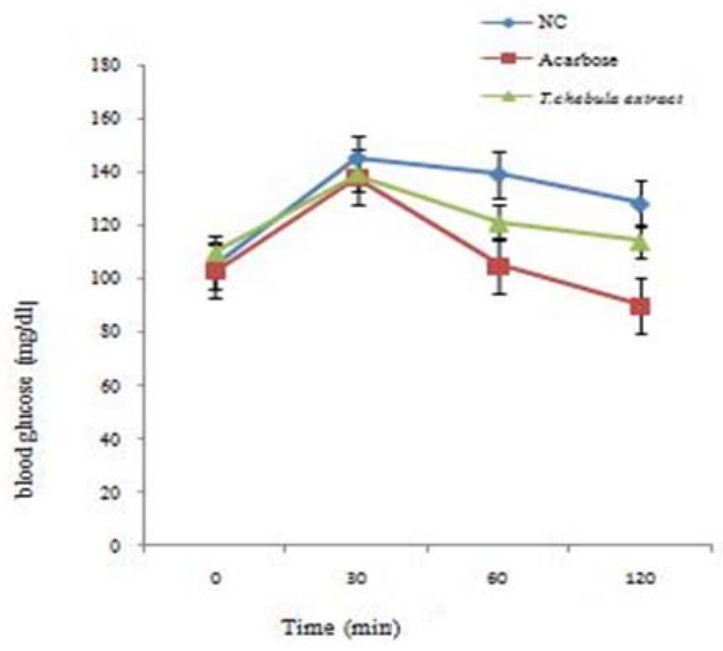

Fig. 2: Oral glucose tolerance test in normal control (NC). Values expressed as the mean $\pm \operatorname{SEM}(n=6)$

\section{Oral maltose tolerance test}

A week after performing the oral glucose tolerance test, all the three groups were loaded with maltose ( $3 \mathrm{gm} / \mathrm{kg}$ body weight). In maltose tolerance test, oral administration of methanol extract of T. chebula leaves $(300 \mathrm{mg} / \mathrm{kg} \mathrm{b} . \mathrm{w})$ to diabetic rats significantly $\left({ }^{*} \mathrm{P}<0.05\right)$ suppressed the rise of postprandial blood glucose level compared to the standard drug acarbose (fig. 3 and 4).

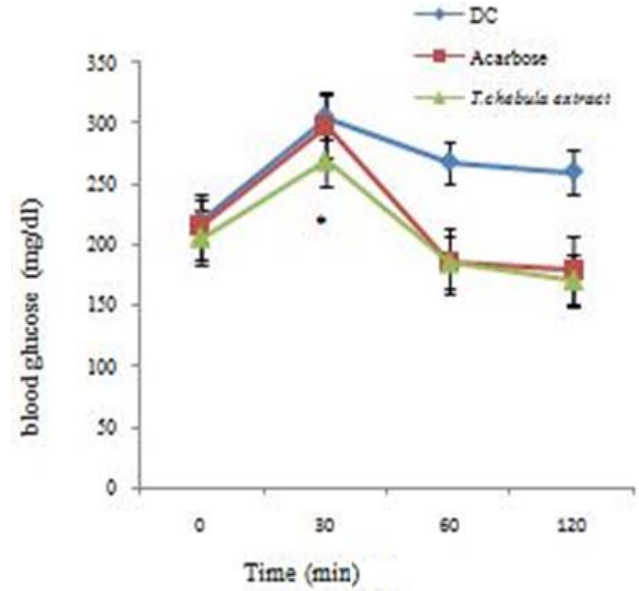

Fig. 3: Oral maltose tolerance test in Diabetic control (DC) values expressed as the mean $\pm \operatorname{SEM}(n=6) . * P<0.05$ compared with standard drug acarbose

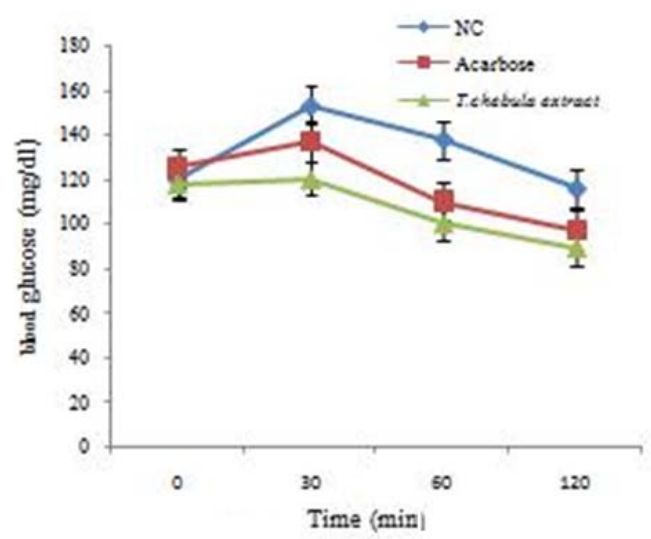

Fig. 4: Oral maltose tolerance test in normal control (NC), values expressed as the mean \pm SEM $(n=6)$

\section{Oral starch tolerance test}

A week after performing the maltose tolerance test, all the three groups were loaded with starch ( $3 \mathrm{gm} / \mathrm{kg}$ body weight). In starch tolerance test, oral administration of standard drug acarbose $(10$ $\mathrm{mg} / \mathrm{kg}$ body weight), $30 \mathrm{~min}$ before oral administration of glucose to normal and diabetic rats was showed higher capability of suppressing the postprandial blood glucose level at 60 and $120 \mathrm{~min}$ compared to methanol extract of $T$. chebula leaves (fig. 5 and 6).

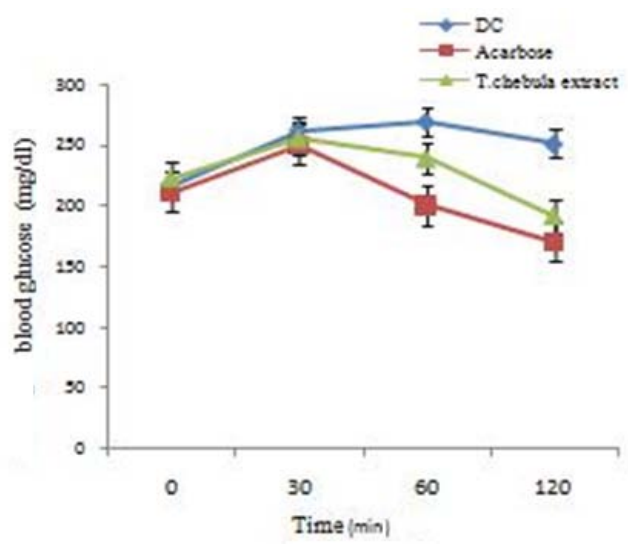

Fig. 5: Oral starch tolerance test in diabetic control (DC), values expressed as the mean \pm SEM $(n=6)$ 


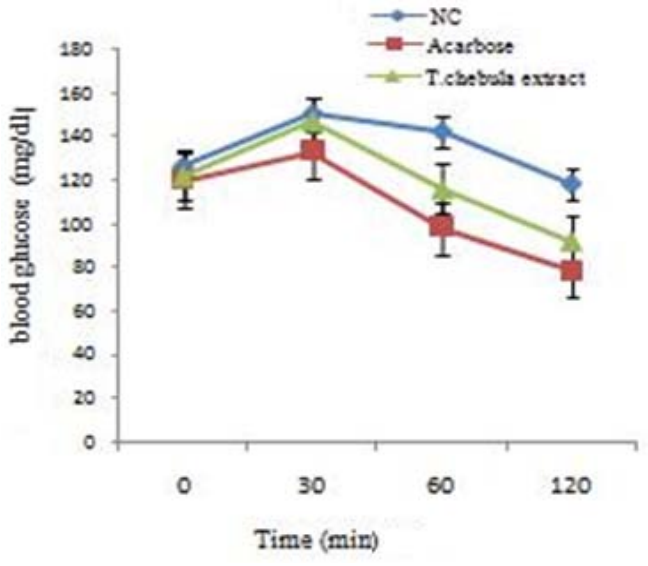

Fig. 6: Oral starch tolerance test in normal control (NC), values expressed as the mean $\pm \operatorname{SEM}(n=6)$

Bioassay-guided fractionation of crude methanol extract of $T$. chebula leaves

The crude methanol extract being the most efficacious extract was later subjected to column chromatography for isolation of the active fraction using a different solvent system of increasing polarity. The column chromatography of crude methanol extract of $T$. chebula leaves using different solvent systems yielded 18 fractions. The collected fractions were later combined into six main fractions based on the Rf (Retention factor) value obtained by analytical thin layer chromatography. The in vitro enzyme inhibition study revealed that Fraction 5 (f5) demonstrated moderate alpha-amylase inhibition (IC50-42.86 $\pm 0.56 \mu \mathrm{g} / \mathrm{ml}$ ) compared to acarbose (IC50-45.06 $\pm 1.01 \mu \mathrm{g} / \mathrm{ml}$ ). However, the active fraction (f5) showed highest $(\mathrm{P}<0.01)$ alpha-glucosidase inhibition with a very minimum IC50 value of $39.58 \pm 0.98 \mu \mathrm{g} / \mathrm{ml}$ compared to acarbose (IC50$55.56 \pm 1.07 \mu \mathrm{g} / \mathrm{ml}$ ) (fig. 7 and 8).

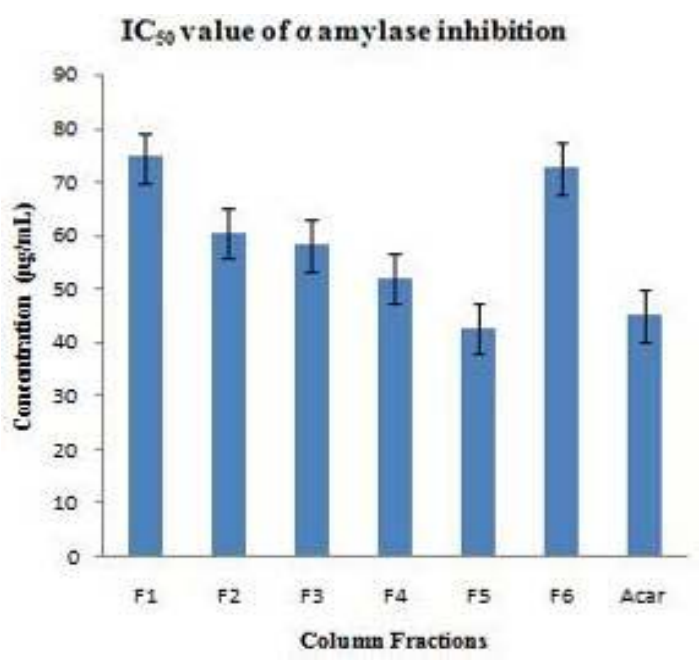

Fig. 7: Alpha amylase inhibition of selected six fractions, values are expressed as mean \pm SEM $(n=3)$

Due to its mild alpha-amylase and high alpha-glucosidase inhibition activity, the fraction (f5) further selected for in vivo study in alloxan-induced diabetic rat model. In vivo maltose tolerance test of (f5) revealed that the leaves of $T$. chebula was capable of retarding the postprandial hyperglycemia significantly $\left({ }^{*} \mathrm{P}<0.05,{ }^{* *} \mathrm{P}<0.01\right.$ ) from $245 \mathrm{mg} / \mathrm{dL}$ (reading taken at $\left.30 \mathrm{~min}\right)$ to $172 \mathrm{mg} / \mathrm{dL}$ (reading taken $120 \mathrm{~min}$ ) interval of time (fig. 9) compared to acarbose $(230 \mathrm{mg} / \mathrm{dL}$ to $197 \mathrm{mg} / \mathrm{dL}$ ) during the studied time interval (fig. 10).

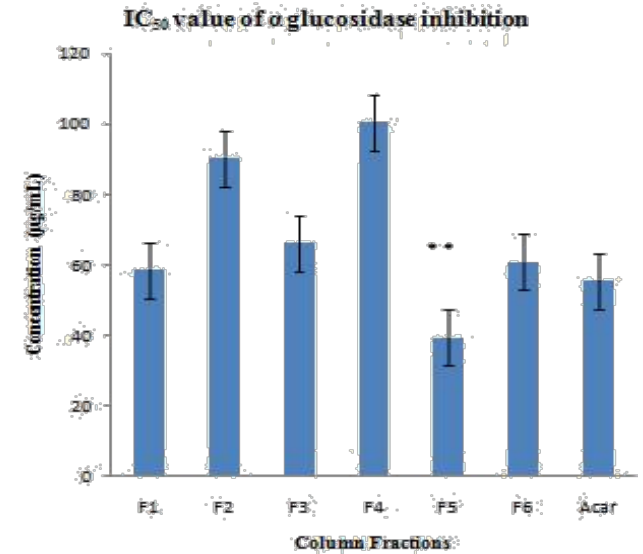

Fig. 8: Alpha-glucosidase inhibition of selected six fractions, values are expressed as mean $\pm \operatorname{SEM}(n=3),{ }^{* *} \mathrm{P}<0.01$ when compared with standard drug acarbose

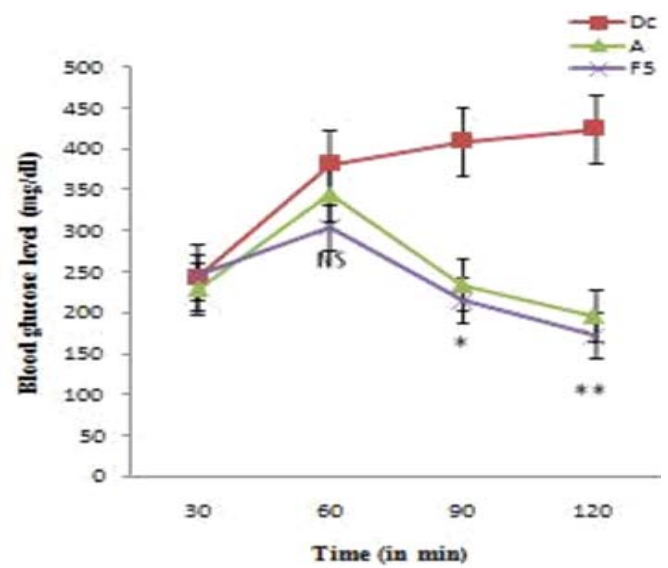

Fig. 9: Maltose tolerance test of $F 5$ in diabetic rats, ${ }^{*} P<0.05$, ${ }^{* *} \mathrm{P}<\mathbf{0 . 0 1}$ when compared to normal control. $\mathrm{A}=$ Acarbose, $\mathrm{f} 5=$ Fraction 5, NC = Normal control, NS = Not significant, values are expressed as mean $\pm \operatorname{SEM}(n=6)$

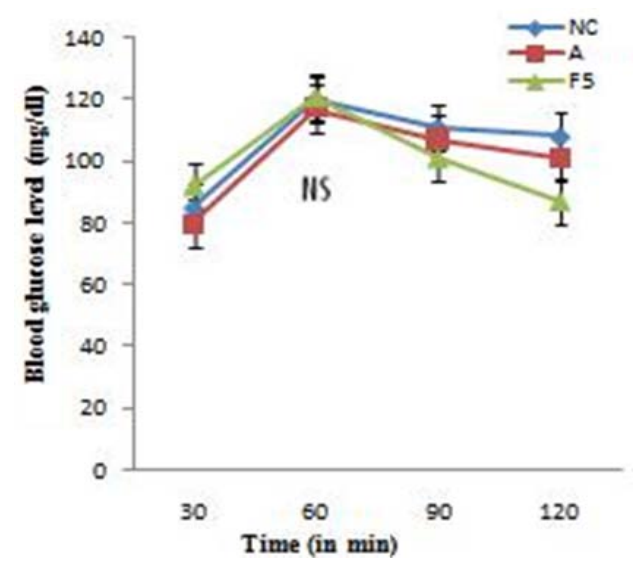

Fig. 10: Maltose tolerance test of $F 5$ in normal rats. $* P<0.05$, $* * \mathbf{P}<0.01$ when compared to diabetic control. $\mathbf{A}=$ Acarbose, $\mathbf{f} 5=$ Fraction 5, NC= Not significant, values are expressed as mean $\pm \operatorname{SEM}(n=6)$

The fraction (f5) demonstrated better result than acarbose in a diabetic group, however, when accessed in normal rat loaded with maltose, it was not found to be significant when compared statistically. The IR spectrum of the fraction exhibited broadband in the range, $3000-3500 \mathrm{~cm}-1$ which are generally attributed to the- $\mathrm{OH}$ 
stretching while the band observed at $1652 \mathrm{~cm}^{-1}$ corresponds to $\mathrm{C}=0$ stretching (fig. 11). The bands observed in the range, 2833.992947.68 contributes to alkane $\mathrm{C}-\mathrm{H}$ bond, 1540.54-1652.69-1500 $\mathrm{cm}^{-1}$ are the due presence of $\mathrm{N}-\mathrm{H}$ bonding, 1418.14-1506.68 are due to alkane $\mathrm{C}-\mathrm{H}$ bond, while the ones at 1113.97 are due to ester linkage and that of $1000 \mathrm{~cm}^{-1}$ to $500 \mathrm{~cm}^{-1}$ are assigned to aromatic
$\mathrm{C}-\mathrm{H}$ bending vibration. The FTIR analysis demonstrated the presence of several functional groups in the most active fraction (f5). Thin layer chromatographic separation of (f5) yielded another subfraction (f5a). The subfraction on HPLC analysis revealed the presence of the gallic acid as a major constituent (fig. 12 and 13).

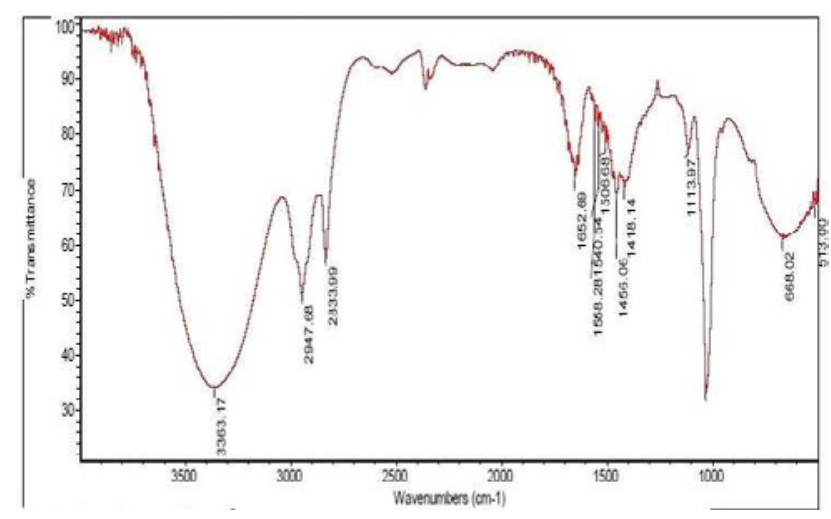

Fig. 11: FTIR spectra obtained for the active fraction (f5)

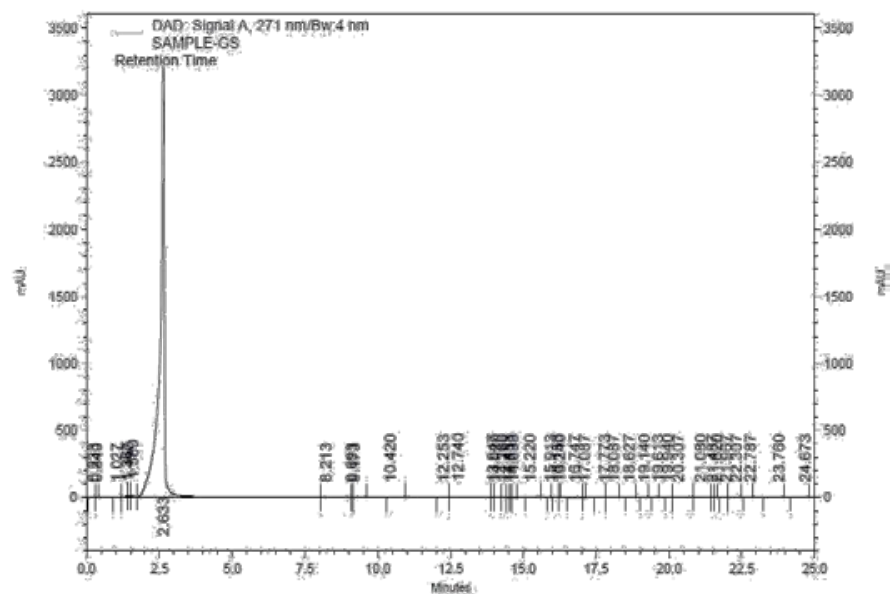

Fig. 12: HPLC spectra of gallic acid standard

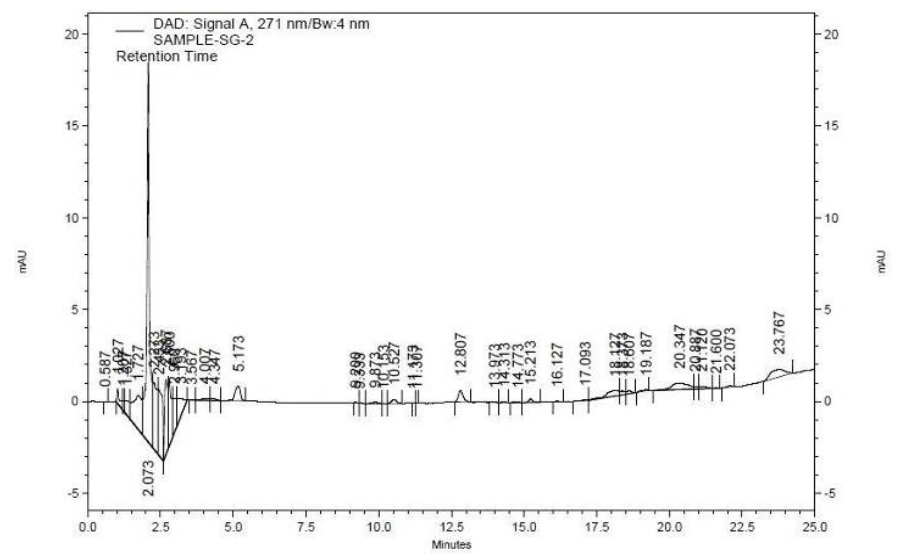

Fig. 13: HPLC spectra of gallic acid isolated from $T$. chebula Retz leaves

Diabetes mellitus is one of the fast-growing health problems in both developing and developed nations.

Postprandial hyperglycemia that occurs due to impaired glucose tolerance (IGT) is alone a factor to double the risk of cardiovascular disease (CVD) [12-15]. There are many previous reports on the potentiality of the fruit part of $T$. chebula to inhibit enzyme alphaglucosidase [16-18]. Several earlier studies conducted on the fruit part of $T$. chebula demonstrated potent maltase inhibitory activity due to the presence of three active ellagitannin (chebulanin, chebulagic acid and chebulinic acid [19]. Plant-derived hydrolyzable tannin is known to be responsible for varied pharmacological 
activity including antidiabetic [20-24]. Gallic acid being one of the widely spread hydrolyzable tannins of $T$. chebula possess very high antioxidant and hypoglycemic property $[25,26]$. Recent studies indicate that plant-derived ploy phenols, because of its antioxidant and anti-inflammatory properties, attribute maximum towards the hypoglycemic effect via several modes like reduction of the intestinal absorption of dietary carbohydrate, improvement of $\beta$-cell function, improvement of insulin action, modulation of the some enzymes involved in glucose metabolism [27-30]. The enzyme $\alpha$ glucosidase inhibitors fall under one of the categories of oral hypoglycemic agents that are generally used for the treatment of diabetes. $\alpha$-glucosidase inhibitory compounds are abundant in nature, and those with very promising inhibitory potentiality can be clinically employed for treating diabetes mellitus type 2 .

\section{CONCLUSION}

The present study concludes that a leaf of $T$. chebula is a potential inhibitor of enzyme alpha-glucosidase that plays a crucial role in intensifying the postprandial hyperglycemic condition. In future, more vigorous and authentic screening of ethnic knowledge-based antidiabetic plants is needed to be done, for the development of some effective bio formulations. Such formulations in the coming future will definitely combat metabolic syndrome like diabetes and complications associated with the disease.

\section{ACKNOWLEDGMENT}

Authors are thankful to Advanced level Institutional Biotech HUB, Department of Biotechnology, Gauhati University for providing the instrumentation and infrastructure facility for performing the research work. Authors are also thankful to Dr. G. C Sharma, curator, Department of Botany, for identification and authentication of the plant material.

\section{AUTHORS CONTRIBUTIONS}

Jayashree Dutta has designed and performed the experiments. M. C Kalita assisted in the preparation of the manuscript. Both the authors have read and approved the content of the manuscript.

\section{ABBREVIATION}

T. Chebula-Terminalia chebula, FTIR-Fourier transform infrared spectroscopy, HPLC - High-performance liquid chromatography, MeOH-Methanol, TLC-Thin layer chromatography, f5-Fraction 5, PPHG-Postprandial hyperglycemia, IC50-Half-maximal inhibitory concentration, CVD-Cardiovascular diseases, IGT-Impaired glucose Intolerance.

\section{CONFLICT OF INTERESTS}

The authors declare no conflicts of interest

\section{REFERENCES}

1. Satyanarayana U, Chakrapani A. Insulin, glucose, homeostasis and diabetes mellitus. Biochemistry. India (3rd edn): Elsevier; 2006. p. 680-1.

2. Stang J, Story M. Guidelines for Adolescent Nutrition Services; 2005. p. 167-82.

3. Guariguata L, Nolan T, Beagley J, Linnenkamp U, Jacqmain O. International Diabetic Federation Diabetes atlas, 6 6 $^{\text {th }}$ edn; 2013.

4. Hurel SJ, Mohan V. Clinical decision making: managing postprandial hyperglycemia. J Assoc Physicians India 2006;54:871-6.

5. Yadav R, Tiwari P, Dhanaraj E. Risk factors and complications of type 2 diabetes in Asians. Curr Res Information Pharm Sci 2008;9 Suppl 2:8-12.

6. Gupta PC. Biological and pharmacological properties of Terminalia chebula Retz. (Haritaki)-an overview. Int J Pharm Pharm Sci 2012;4 Suppl 3:62-8.

7. Sabu MC, Kuttan R. Anti-diabetic activity of medicinal plants and its relationship with their antioxidant property. J Ethnopharmacol 2002;81 Suppl 2:155-60.

8. Murali YK, Anand P, Tandon V, Singh R, Chandra R, Murthy PS. Long-term effects of Terminalia chebula Retz. on hyperglycemia and associated hyperlipidemia, tissue glycogen content and in vitro release of insulin in streptozotocin-induced diabetic rats. Exp Clin Endocrinol Diabetes 2007;115 Suppl 10:641-6.

9. Rao NK, Nammi S. Antidiabetic and renoprotective effects of the chloroform extract of Terminalia chebula retz. seeds in streptozotocin-induced diabetic rats. BMC Complement Altern Med 2006;6:17.

10. Bernfeld P. Amylases, a and b. Methods in Enzymology. New York (NY), London (UK): Academic Press; 1995;2:149-58.

11. Artanti N, Firmansyah T, Darmawan A. Bioactivities evaluation of indonesian mistletoes (Dendrophthoe pentandra (L.) Miq. leaves extracts. J Appl Pharm Sci 2012;2:24-7.

12. Singh U, Singh S, Kochhar A. Therapeutic potential of antidiabetic nutraceuticals. Phytopharmacology 2012;2 Suppl 1:144-69.

13. Hussain SA, Ahmed ZA, Mahwi TO, Aziz TA. Effect of quercetin on postprandial glucose excursion after mono-and disaccharides challenge in normal and diabetic rats. J Diabetes Mellitus 2012;2 Suppl1:82-7.

14. Dutta Jayashree, Kalita MC. In vitro hypoglycemic evaluation of seven culinary plants of North East India against type 2 diabetes. Asian J Pharm Clin Res 2016;9:209-12.

15. Jaiswal N, Srivastava SP, Bhatia V, Mishra A, Srivastava AK, Tamrakar AK, et al. Inhibition of alpha-glucosidase by Acacia nilotica prevents hyperglycemia along with the improvement of diabetic complication via aldose reductase inhibitors. J Diabetes Metab 2012;6:2-7.

16. Gao H, Huang YN, Gao B, Kawabata J. Chebulagic acid is a potent $\alpha$ glucosidase inhibitor. Biosci Biotechnol Biochem 2008;72 Suppl 2:601-3.

17. Gholamhoseinian A, Fallah H, Sharifi F, Mirtajaddini M. The inhibitory effect of some iranian plants extracts on the alphaglucosidase. Iran J Basic Med Sci 2008;11 Suppl 1:1-9.

18. Senthilkumar GP, Subramanian SP. Biochemical studies on the effect of Terminalia chebula on the levels of glycoproteins in streptozotocin-induced experimental diabetes in rats. J Appl Biomed 2008;6:105-15.

19. Huang YN, Zhao DD, Gao B, Zhong K, Zhu RX, Zhang Y, et al. Anti-hyperglycemic effect of chebulagic acid from the fruits of Terminalia chebula retz. Int J Mol Sci 2012;13 Suppl 5:6320-33.

20. Yin Z, Zhang W, Feng F, Zhang Y, Kang W. Alpha-glucosidase inhibitors isolated from medicinal plants. Food Sci Human Wellness 2014;3 Suppl 4:136-74.

21. Mahajan A, Pai N. Simultaneous isolation and identification of phytoconstituents from Terminalia chebula by preparative chromatography. J Chem Pharm Res 2010;2:97-103.

22. Klika KD, Ammar S, Jari S, Marja K, Jyrki L, Petri T, et al. The structural and conformational analyses and antioxidant activities of chebulinic acid and its thrice-hydrolyzed derivative, 2, 4-chebuloyl- $\beta$-D glucopyranoside, isolated from the fruit of Terminalia chebula. Arch Org Chem 2004;7:83-105.

23. Thinkratok A, Supkamonseni N, Srisawat R. Inhibitory potential of the Rambutan rind extract and tannin against alpha-amylase and alpha-glucosidase activities in vitro. International Conference on Food, Biological and Medical Sciences; 2014. p. 44-8.

24. Boath AS, Grussu D, Stewart DD, Mc Dougall GJ. Berry polyphenols inhibit digestive enzymes: a source of potential health benefits. Food Dig 2012;3:1-7.

25. Gangdhar $\mathrm{M}$, Patil $\mathrm{B}$, Yadav $\mathrm{Sl}$, Datta $\mathrm{S}$. Isolation and characterization of gallic acid from Terminalia Bellerica on carbohydrate regulatory enzymes system in vitro. Int J Res Ayurveda Pharm 2011;2 Suppl 2:559-62.

26. Coman C, Dumitriţa Rugina O, Socaciu C. Plants and natural compounds with antidiabetic action. Not Bot Horti Agrobo 2012;40 Suppl 1:314-25.

27. Bahadoran Z, Mirmiran P, Azizi F. Dietary polyphenols as potential nutraceuticals in the management of diabetes: a review. J Diabetes Metab Disord 2013;12 Suppl 1:43.

28. Govindappa MA. Review on the role of plant (s) extracts and its phytochemicals for the management of diabetes. Diabetes Metab 2015;6 Suppl 7:1-38.

29. Pandita NS, Vaidya AS. Therapeutic potential of plant phenolics for the management of diabetic retinopathy. Pharm Crops 2014;5 Suppl 1:29-38. 